\title{
The Conceptual Design Experience of Sea-Going Ships with Alternative Propulsion System, Equipped with Dual-Mode Contra Propeller
}

\author{
Anatolij-Branko R. Togunjac ${ }^{1}$, Leonid I. Vishnevsky ${ }^{2}$ and Evgeniy A. Sedykh ${ }^{3}$ \\ 1. Naval Architecture Department, Research and Design Institute for Fishing Fleet, GIPRORYBFLOT, 8ul. Instrumentalnaya, St. \\ Petersbur 197022, Russia \\ 2. Krylov State Research Centre, 44 Moskovskoye Shosse, St. Petersburg 196158, Russia \\ 3. Research and Design Institute for Fishing Fleet, GIPRORYBFLOT, 8 ul. Instrumentalnaya, St. Petersburg 197022, Russia
}

\begin{abstract}
The paper presents a technical solution which provides energy saving at full speed, as well as duplication of screw propeller and main propulsion system incase it's out of order. The description of the corresponding device, designed for transport refrigerator ship, is shown as well as its location on board. Value of energy saving from the use of contra propeller is estimated. The results of the assessment required power to move the ship at low speed by the action of the contra propeller operating in the reactive mode are demonstrated. It is shown, that the ship equipped with the proposed device will get the additional class notation related to the redundancy or duplication of the propulsion system of Russian Maritime Register of Shipping.
\end{abstract}

Key words: Alternative propulsion system, dual mode contra propeller, multipurpose propulsor.

\section{Introduction}

The necessity to duplicate the components of propulsive complexes is extremely important for safety of navigation of the world civil fleet and it is supported by the fact that leading classification societies have entered appropriate signs into their class notations [1]. The Russian Maritime Register of Shipping has entered into class notation a number of signs that specify the rate of propulsive system components back up. The world classification societies have set up the following requirements with regard to the minimal emergency speed running and environmental conditions (Table 1).

The comparative analyses of the classification societies' requirements related to the redundancy or duplication of the propulsion system showed that there is no common approach to the issue (see Table 1).

Corresponding author: Anatolij-Branko R. Togunjac, Ph.D., naval architect, research fields: hydrodynamics of propeller, maritime engineering sciences.
Besides, the LR и GL require to provide the damaged ship maneuverability as well.

The ship's propulsion system casualty results in the loss of speed and, consequently, may cause the ship's wreck due to stability loss, grounding or stranding during a storm conditions. Prevention of such casualties is extremely important for ships sailing in the most vulnerable sea areas. The following safe return-to-port or "Take Me Home" propulsion solutions for the single-engine main propulsion plant exist and are based on the use of:

- autonomously driven retractable azimuthing thruster [2];

- propulsive unit that combines conventional screw propeller and autonomously driven azimuthing thruster behind it [3] or active rudder;

- new generation multi-purpose shaft generator plants that can operate in a propeller motor mode, or ancillary electric propulsion motors (Power Take In/Power Take of application) $[4,5]$; 
- autonomously driven contra propeller [6, 7], as part of the alternative propulsion system.

Currently ship owners are interested to buy vessels equipped with such propulsion plants that can easily provide back up of their components and in case of the main engine breakdown keep ship on its way, even though this technical solution does not add a symbol to the ship's class notation [4].

The most suitable solution from the point of equipment lay-out and service onboard sea-going vessels might be represented by an option foreseeing alternative propulsion plant equipped with a dual-mode contra propeller.

As an example, consider a transport refrigerator conceptual design (TR-1500). The principal dimensions and hydrostatic particulars are given in Table 2.

\section{Description of the Alternative Propulsion System Equipped with Duel-Mode Contra Propeller}

The alternative propulsion plant consists of two main components: autonomous engine and PSU (propulsive-and-steering unit) with dual-mode contra propeller.

The autonomous engine is installed in the after end of ship and power is transmitted to the dual-mode contra propeller by means of a vertical shaft located inside the semi spade rudder support horn (Fig. 1).

The dual mode contra propeller forms a constituent part of MTBP (multi-functional two-stage blade propulsor). The contra propeller (MTBP stern stage) is located behind the screw propeller (MTBP front stage) and is, actually, a steering thruster controllable pitch

Table 1 Requirements related to the redundancy or duplication of the propulsion system applied by classification societies with regard to minimal speed running.

\begin{tabular}{lll}
\hline Society & Minimal speed, knots & Environmental conditions \\
\hline ABS & Not required & Wind speed of $17 \mathrm{~m} / \mathrm{sec}$, significant wave of $4.5 \mathrm{~m}$ \\
DNV & 6 & BF8 weather conditions and corresponding wave conditions \\
LR & 7 & Not required \\
BV & 7 & Normal weather condition: BF5 \\
GL & 7 or corresponding to 50\% propulsion power & Wind speed: 5 on Beaufort scale, significant wave height of 2,8m \\
RINA & 7 & Calm sea according to MSC.1/Circ.1053 (BF 5) \\
RMRS & 6 or corresponding to 50\% propulsion power (RP-1A) & Normal weather condition: BF5
\end{tabular}

ABS: American Bureau of Shipping; DNV: Det Norske Veritas; LR: Lloyd's Register of Shipping; BV: Bureau Veritas; GL: Germanischer Lloyd; RINA: Registro Italiano Navale; RMRS: Russian Maritime Register of Shipping.

Table 2 The principal dimensions of transport refrigerator R-1500.

\begin{tabular}{lll}
\hline Name of geometrical specifications and units of measurement & Designation & Value \\
\hline Length between perpendiculars, $\mathrm{m}$ & $\mathrm{L}_{\mathrm{pp}}$ & 93.4 \\
Waterline length, $\mathrm{m}$ & $\mathrm{L}$ & 94.6 \\
Breadth, $\mathrm{m}$ & $\mathrm{B}$ & 14.7 \\
Draught, $\mathrm{m}$ & $\mathrm{T}$ & 5.8 \\
Longitudinal centre of buoyancy, $\mathrm{m}$ & $\mathrm{X}_{\mathrm{c}}$ & -0.5 \\
Rising of the propeller centre over the base line, $\mathrm{m}$ & $\mathrm{Z}_{\mathrm{s}}$ & 2.25 \\
Depth to upper deck, $\mathrm{m}$ & $\mathrm{H}_{\mathrm{B}}$ & 8.2 \\
& $\mathrm{~L} / \mathrm{B}$ & 6.43 \\
& $\mathrm{~B} / \mathrm{T}$ & 2.53 \\
Block coefficient $\left(\mathrm{L}_{\mathrm{pp}}\right)$ & $\mathrm{C}_{\mathrm{Bpp}}$ & 0.665 \\
Midship section coefficient & $\mathrm{C}_{\mathrm{M}}$ & 0.94 \\
Displacement, $\mathrm{m} 3$ & $\nabla$ & 5300 \\
\hline
\end{tabular}


propeller. The multi-functionality is understood to mean the ability of the propulsor to provide the following modes of operation: full speed, maneuverability at any speed, extremely low speed and emergency maneuvering speed. The MTBP requires to install in the aft end of the ship an autonomous engine transmitting power to the dual-mode contra propeller when operating in reactive mode.

The principal modes of MTBP operation are shown in Fig. 2. The dual-mode feature of the contra propeller is understood to mean its ability to work both in energy saving mode as a stationary contra propeller (Fig. 2a) and in reactive mode (Fig. 2 b-d) as a steering thruster screw propeller.
At low speed and maneuvering modes (Fig. 2c and 2d) the dual-mode contra propeller is operating as a screw propeller of a steering thruster which is extremely important while maneuvering in harbors, narrow waters and mooring operations.

\section{The Lay-out of Alternative Propulsion System with Dual-Mode Contra Propeller in the Transport Refrigerator after End}

The Caterpillar C9 Acert $375 \mathrm{~kW}$ marine diesel engine (size in $\mathrm{m}: \mathrm{LxH}=1.198 \times 0.983$ ) is chosen as the main engine of an alternative propulsion system. The way it is placed inside the hull of a ship leaves space sufficient for a PM 15M1-2 (the steering engine

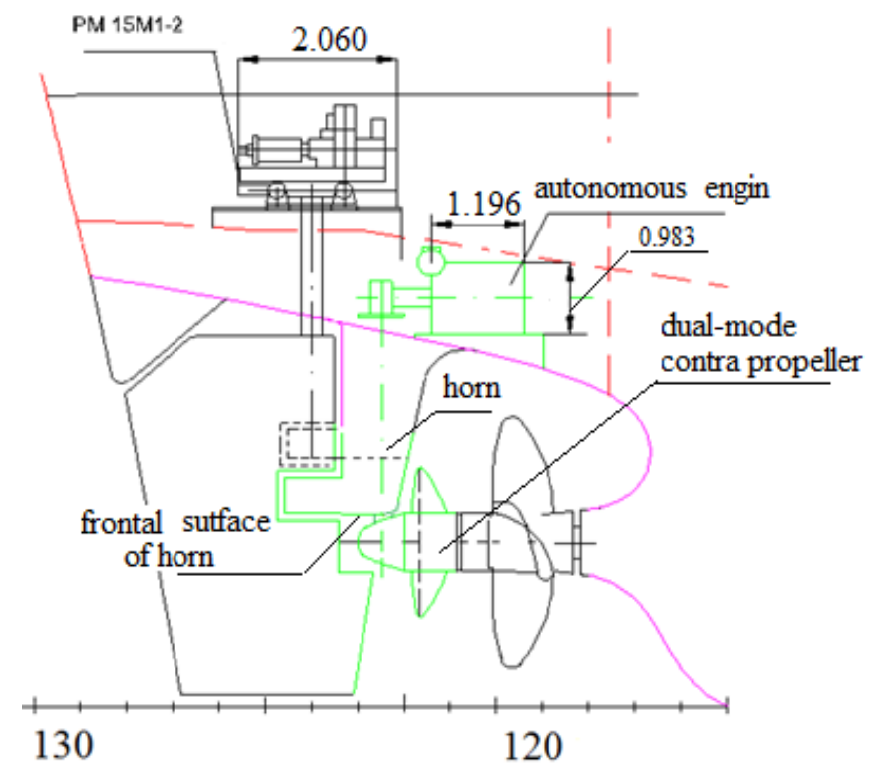

Fig. 1 The TR-1500 aft end with alternative propulsion system with dual-mode contra propeller operating as a propulsor. - Rudder support horn design option.

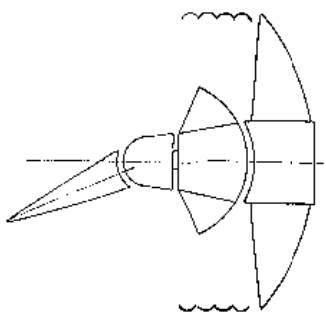

a

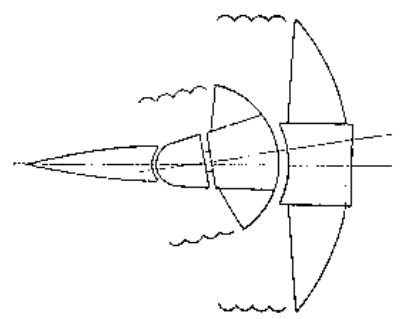

b

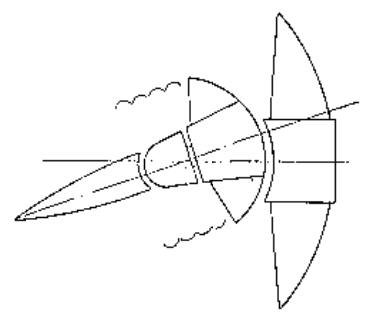

c

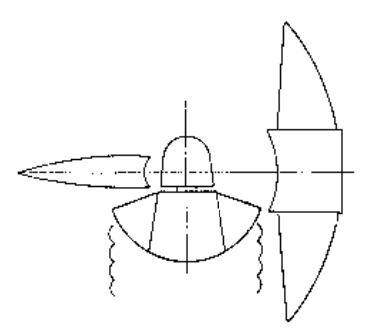

d

Fig. 2 The principal diagrams showing the multifunctional propulsor operation at different modes: a-full speed and maneuvering, fixed contra propeller; $b$ - propulsor is operating in counter rotating propellers mode; $c$-low or emergency speed and maneuvering, contra propeller is working in reactive mode (puller propeller); $d$-maneuvering, contra propeller in reactive mode (pusher propeller); $\cap \cap \cap \cap$-reactive mode. 
of Russian production) steering engine to be installed onboard the transport refrigerator. (Fig. 1). The steering engine and autonomous diesel engine must be located at different height levels and not be installed on the same deck.

The PSU should be mounted into the lower part of the semi spade rudder support horn on its frontal surface specially designed for this purpose. This method of PSU installation (Fig. 1) makes its assembling and disassembling quick and easy, provides an opportunity to modularize the PSU, autonomous engine and a slew drive which is built into the PSU body. Besides, in case the rudderstock and support horn have suitable design it is possible to replace broken down PSU without docking the ship.

The following geometrical parameters were accepted for the dual-mode contra propeller:

- contra propeller diameter $\mathrm{D}_{\mathrm{K}}=2.05 \mathrm{~m}$ (screw propeller diameter $\mathrm{D}=3.5 \mathrm{~m})$;

- ratio $\mathrm{D}_{\mathrm{K}} / \mathrm{D}=0.586$;

- blade number $Z=5$;

- hub diameter $\mathrm{d}_{\mathrm{cr}}=0.8 \mathrm{~m}$;

- $\operatorname{disc}$ ratioA $/ \mathrm{A}_{\mathrm{d}}=0.45$.

The installation of the PSU with dual-mode contra propeller in the ship's aft end does not lead to any changes in the after peak construction compared to its conventional design (Fig. 1). However the semi spade rudder support horn design might require certain changes (linear dimensions unaffected) as power from the autonomous engine is transmitted to the contra propeller via this support horn.

\section{The Estimation of Energy Saving at Full Speed and of Required Power at Slow Speed as Affected by the Dual-Mode Contra Propeller}

The calculation of ship propulsion was performed according to the program developed by the Blagonravov Institute for Machine Science of the Russian Academy of Sciences (IMASH RAN) [8] (Fig. 3). The estimation of the dual-mode contra propeller as an energy-saving device (see Fig. 2a) showed that its use at speed $\mathrm{V}_{\mathrm{s}}=14.5$ knots resulted in reducing the required power by $196 \mathrm{~kW}$ (from 3,074 down to $2,878 \mathrm{~kW}$ ), i.e. by $\approx 6.5 \%$. The energy saving estimation at full speed was performed using the data collected during comparative model self-propelled tests of vessels with conventional propulsion system and contra propeller-equipped propulsor [9].

Table 3 contains the results of power $\mathrm{P}_{\mathrm{s}}$ required to

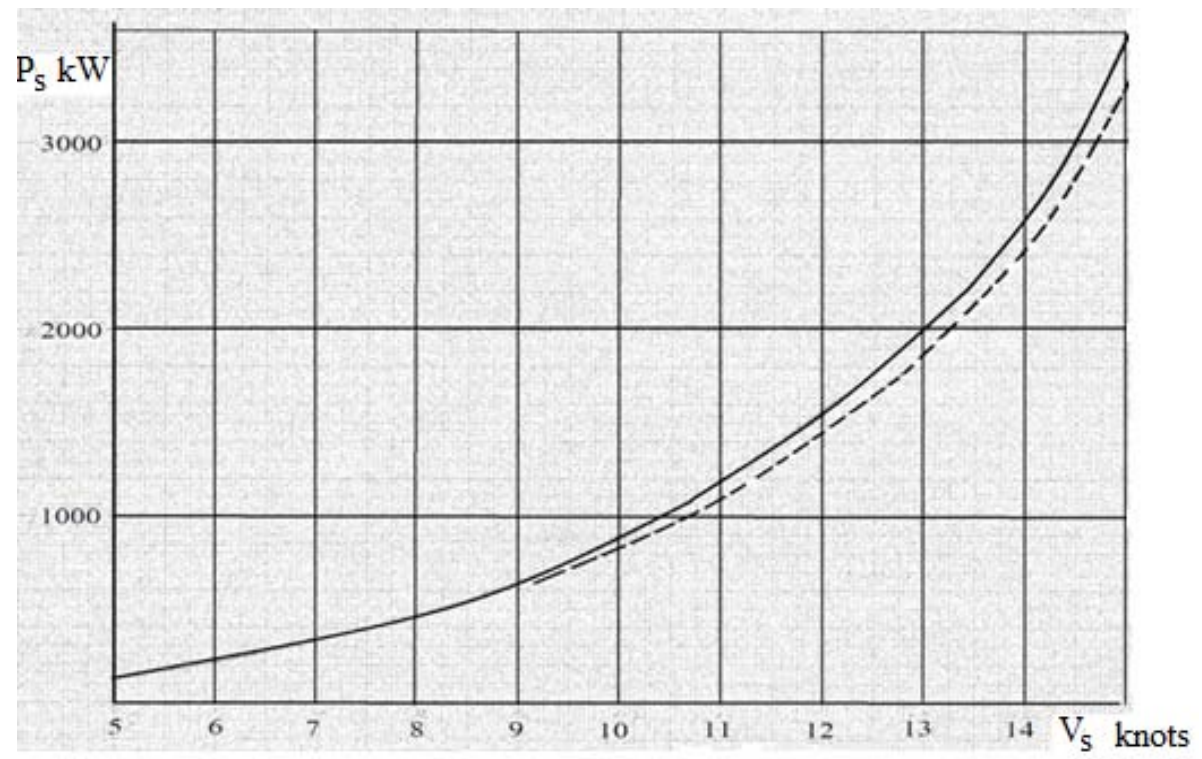

Fig. 3 Power required to run the vessel, $P_{s}=f\left(V_{s}\right)$.

— vessel with a conventional propulsion system; - - vessel with energy-saving device (dual-mode contra propeller, a-mode, Fig. 1) 
Table 3 Required power $P_{s}$ for slow speed of the vessel.

\begin{tabular}{lllll}
\hline $\mathrm{V}_{\mathrm{s}}$ knots & $\begin{array}{l}\mathrm{P}_{\mathrm{e}} \mathrm{kW} \\
\text { Effective power }\end{array}$ & $\begin{array}{l}\mathrm{P}_{\mathrm{s}} \mathrm{kW}- \\
\text { screw propeller }\end{array}$ & $\begin{array}{l}\eta_{\mathrm{D}} \text { - propulsive efficiency for the vessel } \mathrm{P}_{\mathrm{s}} \mathrm{kW} \text { - contra propeller in } \\
\text { reactive mode }\end{array}$ \\
\hline 3 & 31.1 & 69.2 & 0.340 & 93.3 \\
4 & 43.1 & 81.5 & 0.340 & 129.3 \\
5 & 75.7 & 134.8 & 0.340 & 227.2 \\
6 & 123.7 & 212.1 & 0.340 & 371.2 \\
7 & 190.8 & 318.6 & 0.340 & 572.6 \\
\hline
\end{tabular}

run the transport refrigerator at slow speed affected by screw propeller or the contra propeller in reactive mode of operation (see Fig. $2 c, \mathrm{P}_{\mathrm{s}}=\mathrm{P}_{\mathrm{e}} / \eta_{\mathrm{D}} \eta_{\mathrm{B}}$, where $\eta_{\mathrm{B}}=0.98$ - mechanical losses coefficient). The estimation is based on the data regarding the propulsive efficiency $\eta_{D}$ for the vessel with dual-mode contra propeller obtained in the model tank of Krylov State Research Centre.

Table 3 shows that a vessel having the alternative propulsion system with the $375 \mathrm{~kW}$ engine is able to develop slow speed of not less than 6 knots under the affect of the contra propeller.

\section{Conclusions}

The performed study of the after end lay-out of the transport refrigerator used as an example of sea-going vessel proved the compatibility of the alternative propulsion system equipped with a dual-mode contra propeller and a steering engine. The autonomous 375 $\mathrm{kW}$ engine is able to provide the emergency slow speed of not less than 6 knots and, consequently, the vessel will get additional RP-1A symbol to be included into its Russian Shipping Register class notation [10] related to the redundancy or duplication of the propulsion system.

The use of the alternative propulsion system equipped with a dual-mode contra propeller will help to save more than $6 \%$ of energy at full speed mode of operation.

The performed design studies show that the use of the dual-mode contra propeller as screw propeller of the steering thruster at slow speed modes and mooring operations avoid the necessity for a conventional stern thruster installation onboard.

\section{References}

[1] Consideration of Safety Issues Related to the EEDI. IMO document EE-WG1/4, submitted by the International Association of Classification Societies (IACS), 2010.

[2] Libas. 2004. "Revolutionary Purse Seine Netter." Fishing News International 43 (8).

[3] Levander, O. 2007. "New Concepts in Ferry Propulsion." Scandinavian Shipping Gazette.

[4] Poljak, D., Mandekic, J., Adum, I., and Slapnicar, V. 2006. "Redundant Propulsion and Slow Speed Main Engine Propulsion Trend." In Proceedings of the $17^{\text {th }}$ Symposium on Theory and Practice of Shipbuilding in Memoriam prof. Leopold Sorta. Opatija, 365-71.

[5] Pavletic, L. 2006. "The Presentation of Yard NOS. 680, 681, 683, 687 with Reference to Class Notation RPI.” In Proceedings of the $17^{\text {th }}$ Symposium on Theory and Practice of Shipbuilding in Memoriam prof. Leopold Sorta. Opatija, 19-21, 51-7.

[6] Togunjac, A. R., and Vishnevsky, L. I. 2012. "Fishing Vessel with Multi-Functional Two-Stage-Blade Propulsor, Utility Model Patent № 112886, Official Bulletin of Inventions." Useful Models (3).

[7] Togunjac, A. R., Sedykh, E. A., and Vishnevsky, L. I. 2015. "Cargo Ship with a Multipurpose Two-Stage Balde Propulsor, Useful Model Patent № 150293, Official Bulletin of Inventions." Useful models (4).

[8] Development of Prediction Program for Marine Cargo and Fishing Vessels' Performance. USSR Academy of Sciences, Blagonravov Institute for Machine Science, Leningrad, 1990.

[9] Togunjac Anatolij-Branko, R., Vishnevsky Leonid, I., and Ship Blade Propulsors. 2011. New Technical Solutions, Results of Investigations. SPb.: Sudostroenie.

[10] Rules and Regulations for the Construction and Classification of Sea-Going Vessels. The Russian Maritime Register of Shipping, V.3, 2015. 